\title{
Nitrogen Nutrition Effect on Aeroponic Basil (Ocimum basilicum L.) Catalase and Lipid Peroxidation
}

\author{
George ZERVOUDAKIS ${ }^{1 *}$, George SALAHAS ${ }^{1}$, Maria RODI ${ }^{2}$ \\ ${ }^{1}$ Technological Educational Institute of Western Greece, Department of Agricultural Technology, Terma Theodoropoulou, Amaliada 27200, \\ Greece;gzervou@teimesgr("correspondingauthor);gsal@teimes.gr \\ ${ }^{2}$ UniversityofPatras,MedicalSchool,DepartmentofInternalMedicine,Division of Hematology, Patras_Greece; marodi_biol@yahoo.gr
}

\begin{abstract}
Considering the physiological importance of nitrogen $(\mathrm{N})$ for the plant growth and its controversial role in the plant oxidative status, the objective of this research was to investigate the effect of three different $\mathrm{N}$ nutrition solution concentrations $(1.8,3.6$ and $11.5 \mathrm{mM})$ on leaf and root oxidative stress of aeroponically cultured basil (Ocimum basilicum L.) plants. Catalase (CAT) activity and lipid peroxidation (LP) were used as oxidative stress indexes at two different growth stages (10 and 15 week-old plants respectively). Leaf and root CAT activity was enhanced by the increment of $\mathrm{N}$ concentration at both growth stages of the plants. Especially in younger, high $\mathrm{N}$ nourished plants, 130 and $149 \%$ increments of the leaf and root CAT activities were observed respectively, in comparison with the low $\mathrm{N}$ nourished ones. Moreover, the root enzyme seems to be a bifunctional catalase-peroxidase considering its insensitivity to aminotriazole. On the other hand, root LP seems to be unaffected at this $\mathrm{N}$ concentration range whereas leaf LP was enhanced at high $\mathrm{N}$ levels, especially in younger plants. These results suggest that increased $\mathrm{N}$ nutrition induces oxidative stress mainly in the leaves of aeroponically grown basil plants while the increase of CAT activity probably represents a part of plant's antioxidative defense against potent cellular damage similar to membrane lipid peroxidation.
\end{abstract}

Keywords: ammonium, antioxidative defense, nitrate, peroxidase, oxidative stress

Abbreviation: CAT-catalase; N-nitrogen; LP-lipid peroxidation; ROS-Reactive Oxygen Species

\section{Introduction}

Sweet basil (Ocimum basilicum L.) is one of the most popular culinary herbs of the Lamiaceae family cultivated worldwide. It is also used for cosmetical and pharmaceutical preparations as it contains large amounts of essential oils (Sifola and Barbieri, 2006; Kiferle et al., 2013) and antioxidant polyphenolic compounds with anticancer, antibacterial, antifungal and anti-inflammatory capabilities (Nguyen and Niemeyer, 2008; Nurzynska-Wierdak et al., 2013). Basil is generally cultivated in open field (Kiferle et al., 2013), but it is also commercially produced in greenhouses (Nguyen and Niemeyer, 2008). The major advantage of basil greenhouse hydroponic cultivation is the manipulation of growing conditions such as all-year round production, higher quality and ease of processing of harvested material on account of minimal contamination from pollutants, pests and pathogens (Nguyen and Niemeyer, 2008; Kiferle et al., 2013).

Many biochemical compounds present in plant cells contain nitrogen. Besides, most natural and agricultural ecosystems show dramatic gains in productivity after fertilization with inorganic $\mathrm{N}$, attesting to the importance of this element (Taiz and Zeiger, 2002). On the other hand, plant growth decreases under excessive $\mathrm{N}$ levels, as most plant species show smaller leaves and stunted root systems, and in severe cases plants can be lead to death (Chen et al., 2009). Inorganic $\mathrm{N}$ is available to plants as nitrate $\left(\mathrm{NO}_{3}{ }^{-}\right)$and ammonium $\left(\mathrm{NH}_{4}^{+}\right)$ions varying both temporally and spatially in open fields' soils. Nitrate is generally present in higher concentrations $(1-5 \mathrm{mM})$ than ammonium $(20-200 \mu \mathrm{M})$ in the soil solution of agricultural soils (Hawkesford et al., 2012). In soilless culture, $\mathrm{N}$ is generally supplied as $\mathrm{NO}_{3}{ }^{-}$at concentration close or higher than $10 \mathrm{mM}$ (Kiferle et al., 2013). Although nitrate is more mobile in the soil than ammonium and therefore more available to plants (Hawkesford et al., 2012) plant species can exhibit a differential capacity to take up particular forms of inorganic N. Many studies explore the plants' growth responses towards nutrition with varying $\mathrm{NO}_{3}{ }^{-} \mathrm{NH}_{4}^{+}$ratios (Everett et al., 2010).

Production of Reactive Oxygen Species (ROS) is inevitable even under optimum growth conditions. Under conditions of many environmental stresses, enhanced generation of ROS disturbs the normal redox environment of plant cells and damages the cellular components (Tewari et al., 2007; Zhang L.$\mathrm{X}$ et al., 2007). The role of $\mathrm{N}$ in the plant oxidative status is quite controversial. Some authors suggest that high $\mathrm{N}$ concentrations 
562

improve enzyme antioxidant defense (Štajner et al., 1997; Zhang L.-X. et al., 2007) and decrease LP (Zhang L.-X. et al., 2007) while other studies indicate that different $\mathrm{N}$ levels have no significant effect on LP per se but under water- (Saneoka et al., 2004) or cadmium-stress conditions (Zhang et al., 2014) LP has been decreased with increasing $\mathrm{N}$ levels. Besides, it has been suggested that under $\mathrm{N}$ excess stress conditions $\mathrm{LP}$ was increased (Wei et al., 2009) while $\mathrm{N}$ deficiency enhances both LP and enzyme antioxidant responses (Tewari et al., 2007).

Aeroponic system is a successful cultivation method for several plant species, primarily because of the highly aerobic environment for the plant's roots. Besides, the aeroponic system makes it possible to examine completely intact roots without disturbing or damaging them, and to obtain clean samples without interference from mechanical substrates (Zobel et al., 1976).

Ocimum basilicum L. is an economically interesting plant, field and hydroponically cultivated (Kiferle et al., 2013). In the present study, we examined the effect of three different $\mathrm{N}$ nutrition concentrations on leaf and root oxidative status of aeroponically cultivated sweet basil plants at two different growth stages. The CAT activity and the LP were used as antioxidative defense and oxidative damage indexes, respectively.

\section{Materials and Methods}

\section{Plant growth}

This study was conducted during Autumn-Winter 2013 in an automated glasshouse located at the former Technological Educational Institute of Messolonghi at Western Greece. Sweet basil (Ocimum basilicum L.) seeds were sown in 80 pots with soil and irrigated with water. When the seedlings reached about 10 $\mathrm{cm}$ height, they were transplanted (after washing the roots in order to remove the soil) in the glasshouse at the established novel "Fully Automated Aeroponic Growing System". This closed recirculated aeroponic growing system consisted from three canals (one for each of the nitrogen levels) with three replications. The canals were made up of polystyrene rectangular sections with length $10 \mathrm{~m}$, width $0.67 \mathrm{~m}$ and height $0.30 \mathrm{~m}$, and internal thin plastic layer, to allow reuse of the nutrient solution. They were covered by polystyrene panels with holes on which plants were placed. A high pressure irrigation system of two parallel pipes with aeroponic sprayers was installed inside the structures in the bottom of the canals. The roots of the plants were sprayed by the nutrient solution for $25 \mathrm{~s}$ every $5 \mathrm{~min}$. The system was fully electronically controlled. Plants were grown under natural temperature and daylight conditions. Root zone temperature into growing canals was automatically controlled to $20^{\circ} \mathrm{C}$.

\section{Nutrientsolutions}

The irrigation solutions were prepared at three different $\mathrm{N}$ levels: i) 1.8 (low), ii) 3.6 (medium) and iii) $11.5 \mathrm{mM}$ (high level, usually used in soilless culture) while all the other macro- and micronutrient concentrations remained constant. The solutions contained the following: a) macronutrient levels in $\mathrm{mM}: \mathrm{N}$ (as nitrate plus ammonium, respectively), $\mathrm{NO}_{3}: 1.70,3.40,10.9$ and $\mathrm{NH}_{4}^{+}: 0.1,0.2,0.6 ; \mathrm{K}, 6.5 ; \mathrm{Ca}, 3.0 ; \mathrm{Mg}, 0.9 ; \mathrm{P}, 1.6$ and b) micronutrient levels in $\mu \mathrm{M}$ : Fe, 30.0; $\mathrm{Mn}, 5.0 ; \mathrm{Zn}, 4.0 ; \mathrm{Cu}, 0.75$; $\mathrm{B}, 30.0 ; \mathrm{Mo}, 0.53$. The $\mathrm{pH}$ was adjusted to 5.6-6.0 and the electrical conductivity kept at $1.70 \mathrm{~d} \mathrm{~S} \mathrm{~m}^{-1}$.

\section{Experimentalmeasurements}

All the below measurements were conducted 5 and 10 weeks after the installation of the seedlings to their respective $\mathrm{N}$ nutrition treatment (called younger and older plants, respectively). The leaf samples were taken from healthy, completely expanded leaves of the $3^{\text {rd }}$ node from the top of the shoot. The root samples were taken from lateral roots. For each experiment, the leaf and root sampling were conducted from three plants per $\mathrm{N}$ treatment. The results are the means of three independent experiments.

The samples were collected from the plants, wrapped in plastic bags and transferred immediately to the lab for LP, CAT activity, protein concentration and dry weight estimations. The samples were washed gently with deionised $\mathrm{H}_{2} \mathrm{O}$ and blotted with paper. Similar samples were obtained and either dried to constant weight in an oven at $85^{\circ} \mathrm{C}$ or homogenized.

All reagents were purchased from Sigma (St. Louis, MO, U.S.A.) and Merck (Darmstadt, Germany).

\section{Lipidperoxidation}

The leaf and root samples were ground at $4{ }^{\circ} \mathrm{C}$ under dim light (to prevent artificial LP) in a porcelain mortar with homogenization buffer containing $50 \mathrm{mM} \mathrm{Na} 2 \mathrm{HPO}_{4} \mathrm{pH} 7.2,1$ $\mathrm{mM}$ ethylenediaminetetraacetic acid (EDTA), $1 \mathrm{mM}$ butylated hydroxyanisole (BHA) and $0.15 \%$ ethanol. The homogenization was carried out using $5 \mathrm{~mL}$ buffer per $\mathrm{g}$ fresh sample weight. The homogenate was assayed for LP products by a modified thiobarbituric acid (TBA)-based method (Buege and Aust, 1978). Specifically, $0.5 \mathrm{~mL}$ homogenate was mixed with $0.5 \mathrm{~mL}$ TBA reagent containing $0.5 \%(\mathrm{w} / \mathrm{v})$ TBA, $20 \%(\mathrm{w} / \mathrm{v})$ trichloroacetic acid (TCA) and $0.33 \mathrm{~N} \mathrm{HCl}$. To the resulting mixture was added $5 \mu \mathrm{L} 2 \%(\mathrm{w} / \mathrm{v})$ of the lipid antioxidant BHA (in absolute ethanol) to prevent artificial LP during the assay. The mixture was incubated at $100^{\circ} \mathrm{C}$ for $15 \mathrm{~min}$ and brought to room temperature (RT). To that was added $1 \mathrm{~mL} 1$-butanol, mixed by vigorous vortexing, centrifuged at $15,000 \mathrm{~g}$ for $3 \mathrm{~min}$, and the absorbance determined with a Shimadzu UV-1601 spectrophotometer (Shimadzu Corp., Japan) of the upper butanol layer was measured at 535 and $600 \mathrm{~nm}$ (subtracting the non-specific absorbance) against a sample blank (0.5 mL sample mixed with $0.5 \mathrm{~mL} 20 \%$ TCA in $0.33 \mathrm{~N} \mathrm{HCl}$ and with $5 \mu \mathrm{L} 2 \%$ $\mathrm{w} / \mathrm{v} \mathrm{BHA})$ and a reagent blank $(0.5 \mathrm{~mL}$ homogenization buffer mixed with $0.5 \mathrm{~mL}$ TBA reagent and $5 \mu \mathrm{L} 2 \% \mathrm{w} / \mathrm{v} \mathrm{BHA})$. Absorbance difference $A_{(535-600)}$ was converted to malondialdehyde (MDA) equivalents with the molar extinction coefficient $1.56 \cdot 10^{5} \cdot \mathrm{M}^{-1} \cdot \mathrm{cm}^{-1}$. LP was defined as TBA-reactive substances (TBARS) and was expressed in nmol MDA equivalents per g dry weight.

\section{Catalase activity}

The samples were ground at $4^{\circ} \mathrm{C}$ in a porcelain mortar with homogenization buffer containing $100 \mathrm{mM} \mathrm{K} \mathrm{HPO}_{4} \mathrm{pH} 7.0,1$ mM EDTA, $0.5 \mathrm{mM}$ phenylmethylsulfonyl fluoride (PMSF) and $0.3 \%$ ethanol. The homogenization was carried out using 5 $\mathrm{mL}$ buffer per $\mathrm{g}$ fresh sample weight. The homogenate was centrifuged at $3,300 \mathrm{~g}$ for $5 \mathrm{~min}$, at $4{ }^{\circ} \mathrm{C}$. The resulting supernatant was subsequently used for both CAT activity and protein concentration estimation. Catalase was assayed by its depletion of $\mathrm{H}_{2} \mathrm{O}_{2}$, followed at $240 \mathrm{~nm}$ (Blum and Fridovich, 1983).

The standard CAT assay consists of mixing (in a $30^{\circ} \mathrm{C}$ water bath) $0.85 \mathrm{~mL}$ sample (proper dilution of the homogenate 
supernatant), $0.05 \mathrm{~mL}$ of the homogenization buffer and $0.1 \mathrm{~mL}$ $0.09 \mathrm{M} \mathrm{H}_{2} \mathrm{O}_{2}$ stock solution (made fresh in homogenization buffer). The linear absorbance decrease (vs time) of the assay mixture was measured at $240 \mathrm{~nm}$ in a Shimadzu UV-1601 spectrophotometer. The absorbance decrease rate of consumed $\mathrm{H}_{2} \mathrm{O}_{2}$ was converted to CAT units (U) from a pure CAT standard curve.

The aminotriazole inhibition assay test of CAT consists of mixing $0.85 \mathrm{~mL}$ sample, $0.05 \mathrm{~mL} 0.4 \mathrm{M}$ aminotriazole (made fresh in homogenization buffer) and $0.1 \mathrm{~mL} 0.09 \mathrm{M} \mathrm{H}_{2} \mathrm{O}_{2}$ stock solution. Specifically for the aminotriazole effect experiments, the $\mathrm{H}_{2} \mathrm{O}_{2}$ absorbance decrease of both standard and inhibition assay mixture was measured at a wavelength that the aminotriazole spectrum does not interfere significantly to the $\mathrm{H}_{2} \mathrm{O}_{2}$ one that is $253 \mathrm{~nm}$

\section{Protein concentration}

The protein concentration was determined by a modification of a Coomassie Brilliant Blue-based method (Assimakopoulos et al., 2008). Specifically, $0.063 \mathrm{~mL}$ of various dilutions of the sample (homogenate supernatant) was mixed with $0.02 \mathrm{~mL}$ of $0.5 \%(\mathrm{v} / \mathrm{v})$ Triton X-100 and $0.017 \mathrm{~mL}$ of $6 \mathrm{~N}$ $\mathrm{HCl}$. The mixture was incubated at $100{ }^{\circ} \mathrm{C}$ for $10 \mathrm{~min}$, brought to RT, mixed with $0.9 \mathrm{~mL}$ of $0.033 \%$ (w/v) Coomassie Brilliant Blue G-250 stock reagent (made in $0.5 \mathrm{~N} \mathrm{HCl}$, stirred for 30 min, filtered through Whatman \#1 filter paper by water pump aspiration, and stored in the dark) and incubated for $5 \mathrm{~min}$ at room temperature. The absorbance at $620 \mathrm{~nm}$ (against appropriate sample and reagent blanks) of the mixture was converted to $\mathrm{mg}$ of protein from a Bovine Serum Albumin standard curve, using a Shimadzu UV-1601 spectrophotometer.

\section{Data analysis}

The results were obtained from three independent experiments and expressed as mean \pm standard error of mean (SEM). The D'Agostino-Pearson normality test used in order to test the distribution of data. Statistical differences between the three different nitrogen levels in leaves and roots were calculated using ANOVA test with Tukey's multiple comparison test. The statistical significance level was set at a $=0.05$. Data were plotted and analyzed using GraphPad Prism V5.0.

\section{Results and Discussion}

Catalase was primarily observed in tobacco leaf by Loew (1900) who characterized, named the enzyme and suggested that "there seems to exist no plant and no animal which is without that peculiar enzyme". Catalases and peroxidases are the two major systems for the enzymic removal of hydrogen peroxide $\left(\mathrm{H}_{2} \mathrm{O}_{2}\right)$ in plants. Catalases are highly active enzymes that do not require cellular reductants as they primarily dismutate $\mathrm{H}_{2} \mathrm{O}_{2}$ to $\mathrm{H}_{2} \mathrm{O}$ and $\mathrm{O}_{2}\left(2 \mathrm{H}_{2} \mathrm{O}_{2} \rightarrow 2 \mathrm{H}_{2} \mathrm{O}+\mathrm{O}_{2}\right)$ (Willekens et al., 1995; Mhamdi et al., 2010). The enzyme activity from both basil leaves and roots elevated during the increment of $\mathrm{N}$ nutrition concentrations, though the phenomenon is more intense in younger (Fig. 1A) than in older plants (Fig. 1B). In younger high $\mathrm{N}$ nourished plants, we observed 130 and $149 \%$ statistically significant increments of the leaf $(\mathrm{p}<0.0001)$ and root $(\mathrm{p}<0.05)$ CAT activities, respectively, in comparison with the low $\mathrm{N}$ nourished ones (Fig. 1A). However, the $\mathrm{N}$ nutrition effect on CAT activity is moderated in older plants since the increments are 44 and $55 \%$ for leaves and roots, respectively (Fig. 1B). The $\mathrm{N}$ induced leaf CAT activity increment has been also suggested for sugar beet (Štajner $e t$ al., 1997), maize (Zhang L.-X. et al., 2007) and poplar plants (Zhang et al., 2014) but there are no data about the $\mathrm{N}$ nutrition effect on roots CAT activity. However, it has been suggested that the leaf CAT activity increases under $\mathrm{N}$ deficiency too (Tewari $e t$ al., 2007).

Our results indicate that under all $\mathrm{N}$ concentrations, the younger basil plants' leaf CAT activity is $78-177 \%$ higher than root's activity $(\mathrm{p}<0.0001)$ whereas in older plants this pattern is absent $(\mathrm{p}=\mathrm{ns})$ (Fig. 2A). LeafCAT activity has been also referred to be significantly higher than the root one in maize (Redinbaugh et al., 1990) and barley (Azevedo et al., 1998). On the other hand, the enzyme activity of Citrus young roots has been reported to be higher than the leaves' one (Chouliaras et al., 2004). We also found that in younger plants leaf CAT activity is equal or higher (at high $\mathrm{N}$ nutrition) than in older ones (Fig. 2B) indicating that the leaf enzyme activity may decreases during the plant ageing which is in accordance with findings in maize leaves (Zhang L.-X. et al., 2007) while the opposite phenomenon appears with regard to basil root CAT enzyme (Fig. 2B).

Angiosperm species studied to date all contain three catalase genes. This includes monocots and dicots such as tobacco, Arabidopsis, maize, pumpkin, and rice (Mhamdi et al., 2010). The CAT genes expression in different plants' tissues (photosynthetic, vascular, reproductive and seed) has been classified based on the naming of the tobacco genes i.e. Cat1, Cat2 and Cat3 (Willekens et al., 1995; Mhamdi et al., 2010). Our research shows a quite different activity profile between the leaf and root enzyme. Moreover, a basil CAT inhibition assay test with the presence of $20 \mathrm{mM}$ aminotriazole revealed $67-77 \%$ decrease of the leaf enzyme activity while the root enzyme was decreased only $31-$ $42 \%(\mathrm{p}<0.05)$ (Table 1$)$ which corresponds to in vivo and in vitro findings in tobacco seedlings although both their aminotriazole sensitive and insensitive examined CAT forms were leaf ones (Havir, 1992). Thereby, it seems that in basil roots dominates a bifunctional catalase-peroxidase isoenzyme while in leaves dominates a typical monofunctional CAT considering that bifunctional catalases-peroxidases are insensitive to the classical CAT inhibitor aminotriazole (Willekens et al., 1995; Mhamdi et al., 2010, 2012).

ROS can seriously disrupt normal metabolism through oxidative damage to lipids, proteins and nucleic acids (Chen $e t$ al., 2009). Therefore, LP can be used as a marker of the cellular damage caused by oxidative stress. Responding to different $\mathrm{N}$ nutrition concentrations, root LP seems to be unaffected in both younger and older basil plants (Fig. 3). On the other hand, leaf LP in younger plants shows an $41 \%$ increment which observed in the maximum $\mathrm{N}$ concentration in contrast with the low $\mathrm{N}(\mathrm{p}<0.05)$ (Fig. 3A) while in older plants we observed: i) a $44 \%$ increment in the medium concentration and ii) no effect in the maximum concentration, in comparison with the low $\mathrm{N}$ concentration $(\mathrm{p}=$ ns) (Fig. 3B). In bibliography, there are some controversial results about the effect of $\mathrm{N}$ nutrition to plant leaf LP while there are no results about the effect to root LP. In particular, $\mathrm{N}$ nutrition (with urea as $\mathrm{N}$ source) significantly decreased leaf MDA content (Zhang L.-X. et al., 2007) while other studies indicate that different $\mathrm{N}$ levels (with ammonium nitrate as $\mathrm{N}$ source) have no significant effect on leaf LP per se but under water- (Saneoka et al., 2004) or cadmium-stress conditions (Zhang et al., 2014) LP has been 
decreased with increasing $\mathrm{N}$ levels. Besides, it has been suggested that leaf $\mathrm{LP}$ was increased under both $\mathrm{N}$ deficiency (with $\mathrm{KNO}_{3}$ and $\mathrm{Ca}\left(\mathrm{NO}_{3}\right)_{2}$ as $\mathrm{N}$ source for the control plants) (Tewari et al, 2007) and N excess (with calcium nitrate) stress conditions (Wei et al.,2009).

Table 1. Aminotriazole $(20 \mathrm{mM})$ inhibition effect on leaf and root catalase activity

\begin{tabular}{|c|c|c|}
\hline Nitrogen treatment $(\mathrm{mM})$ & Plant organ & $\%$ inhibition \\
\hline \multicolumn{3}{|c|}{ Younger plants } \\
\hline 1.8 & Leaves & $72 \pm 6 \mathrm{Aa}$ \\
\hline 1.8 & Roots & $42 \pm 1 \mathrm{Bb}$ \\
\hline 3.6 & Leaves & $74 \pm 8 \mathrm{Aa}$ \\
\hline 3.6 & Roots & $35 \pm 8 \mathrm{Bb}$ \\
\hline 11.5 & Leaves & $77 \pm 10 \mathrm{Aa}$ \\
\hline 11.5 & Roots & $32 \pm 10 \mathrm{Bb}$ \\
\hline \multicolumn{3}{|c|}{ Older plants } \\
\hline 1.8 & Leaves & $67 \pm 8 \mathrm{Aa}$ \\
\hline 1.8 & Roots & $31 \pm 7 \mathrm{Bb}$ \\
\hline 3.6 & Leaves & $67 \pm 7 \mathrm{Aa}$ \\
\hline 3.6 & Roots & $31 \pm 4 \mathrm{Bb}$ \\
\hline 11.5 & Leaves & $75 \pm 2 \mathrm{Aa}$ \\
\hline 11.5 & Roots & $38 \pm 9 \mathrm{Bb}$ \\
\hline
\end{tabular}

Data are mean \pm SE $(n=3)$. Means with the different letter are significantly different from each other (Tukey test, $p<0.05$ ). Capital letters represent comparison between leaves and roots. Lower case letters represent comparison between nitrogen treatments.
Our study indicates that under all $\mathrm{N}$ concentrations, the younger basil plants' leaf LP is $35-95 \%$ higher than the root one but in older plants these increments tend to be annihilated with the exception of the medium $\mathrm{N}$ concentration treatment (Fig. 4A). Likewise, leaf LP has been reported to be higher than the root one in tobacco (Popov et al., 2010) and sugar beet (Kiprovski et al., 2014) while the opposite phenomenon has been reported in Bruguiera gymnorrbiza and Kandelia candel (Zhang F.-Q. et al., 2007). Besides, a recent research on maize reported root LP being whether higher or similar with the leaf one, depending on the particular plant genotype (Tang et al.,2010).

Our results also indicate that in younger plants leaf LP is significantly higher (especially at high $\mathrm{N}$ nutrition, likewise the leaf CAT activity) than in older ones (Fig. 4B). In contrast, leaf LP increased during the plant ageing in other plants (Zhang L.-X. et al., 2007). Other researchers compare LP status between younger and older leaves of the same plant that is upper and lower leaves, respectively. Their findings usually suggest increased LP at the lower (older) leaves (Wang et al., 2012) although it has been reported the opposite result too (Dias et al., 2014). On the other hand, root LP seems to be unaffected during ageing of the pant (Fig. 4B). There are inadequate data about the root LP status during the plant ageing although it has been reported that during maize seedling maturation root $\mathrm{LP}$ is increased (Tang et al.,2010).

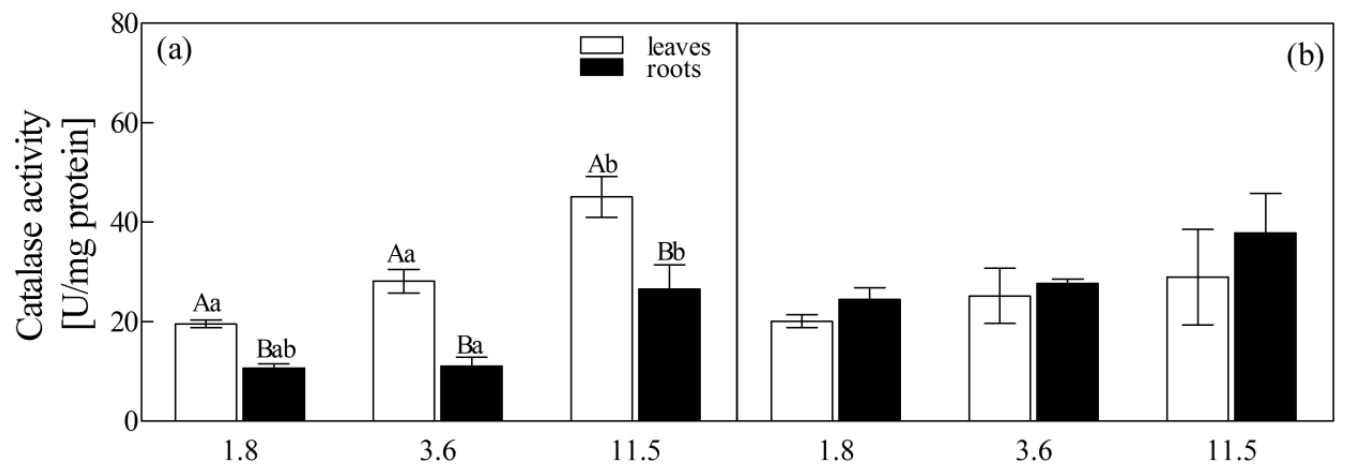

Nitrogen concentration $[\mathrm{mM}]$

Fig. 1. Effect of nitrogen treatments on leaf and root catalase activity of younger (a) and older (b) basil plants

Vertical bars represent mean $\pm S E(n=3)$. Means with the different letter are significantly different from each other (Tukey test, $\mathrm{p}<0.05)$. Capital letters represent comparison between leaves and roots. Lower case letters represent comparison between nitrogen treatments

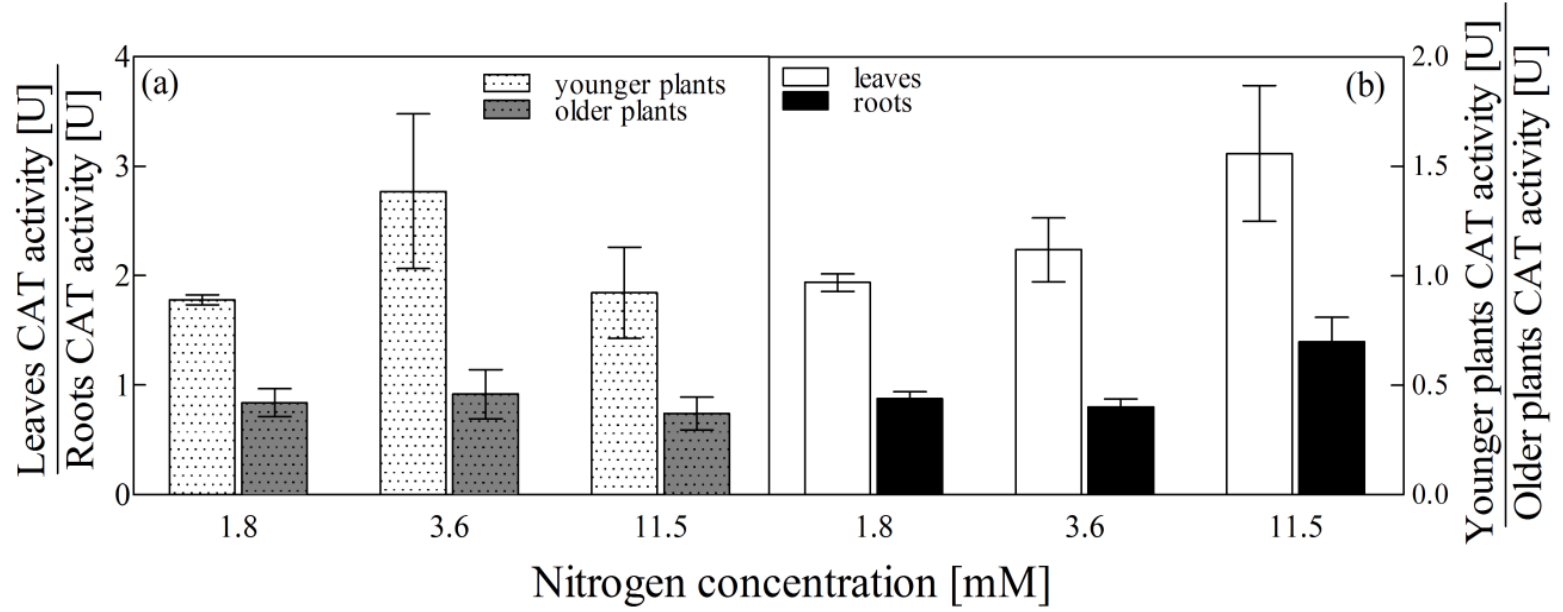

Fig. 2. Effect of nitrogen treatments on a) leaves to roots and b) younger to older plants catalase activity ratios Vertical bars represent mean \pm SE $(n=3)$ 
Although $\mathrm{N}$ is an essential macronutrient element, some $\mathrm{N}$ compounds (ammonium, nitrite etc.) can be toxic for plants (Taiz and Zeiger, 2002; Guo et al., 2007). Nitrate and ammonium are the main sources of $\mathrm{N}$ for crop plants (Kiferle et al.,2013). In many plants, when the roots receive small amounts of nitrate, nitrate is reduced primarily in the roots. As the supply of nitrate increases, a greater proportion of the absorbed nitrate is translocated to the shoot and assimilated there (Taiz and Zeiger, 2002). The first step of the nitrate reduction into nitrite is catalyzed by nitrate reductase in the cytosol, and nitrite is further reduced to ammonium by nitrite reductase in the plastid/chloroplast. Finally, the ammonium assimilation into glutamate by glutamine synthetase/glutamate synthetase (GS/GOGAT) occurs. With the last reaction, plant cells (especially in roots) avoid ammonium toxicity by rapidly converting into amino acids either the absorbed ammonium or the ammonium generated from nitrate assimilation, photorespiration and protein degradation (Taiz and Zeiger, 2002; Guo et al., 2007).
Recent studies investigate the effect of $\mathrm{N}$ deficiency (Tewari $e t$ al., 2007), excess (Wei et al., 2009) or form (Chen et al., 2009) on the oxidative status of plants. It is considered that $\mathrm{N}$ plays an important role in the enzymic antioxidant defense and the lipid peroxidation metabolism of plants (Štajner et al., 1997; Zhang L.X. et al., 2007) especially under different environmental stresses (Saneoka et al., 2004; Zhang et al., 2014). There are several methodological differences between the studies which explore the influence of $\mathrm{N}$ nutrition in basil plants, such as hydroponic (Kiferle et al., 2013) or field culture (Sifola and Barbieri, 2006), winter (Nurzynska-Wierdak et al., 2013), spring (Kiferle et al., 2013), summer or fall seeding (Nguyen and Niemeyer, 2008) and a wide range of $\mathrm{N}$ treatment concentrations from $0.1 \mathrm{mM}$ (Nguyen and Niemeyer, 2008) to $0.9 \mathrm{~g} \mathrm{dm}^{-3}$ of growing medium (NurzynskaWierdak et al. 2013) that is $64 \mathrm{mM}$.

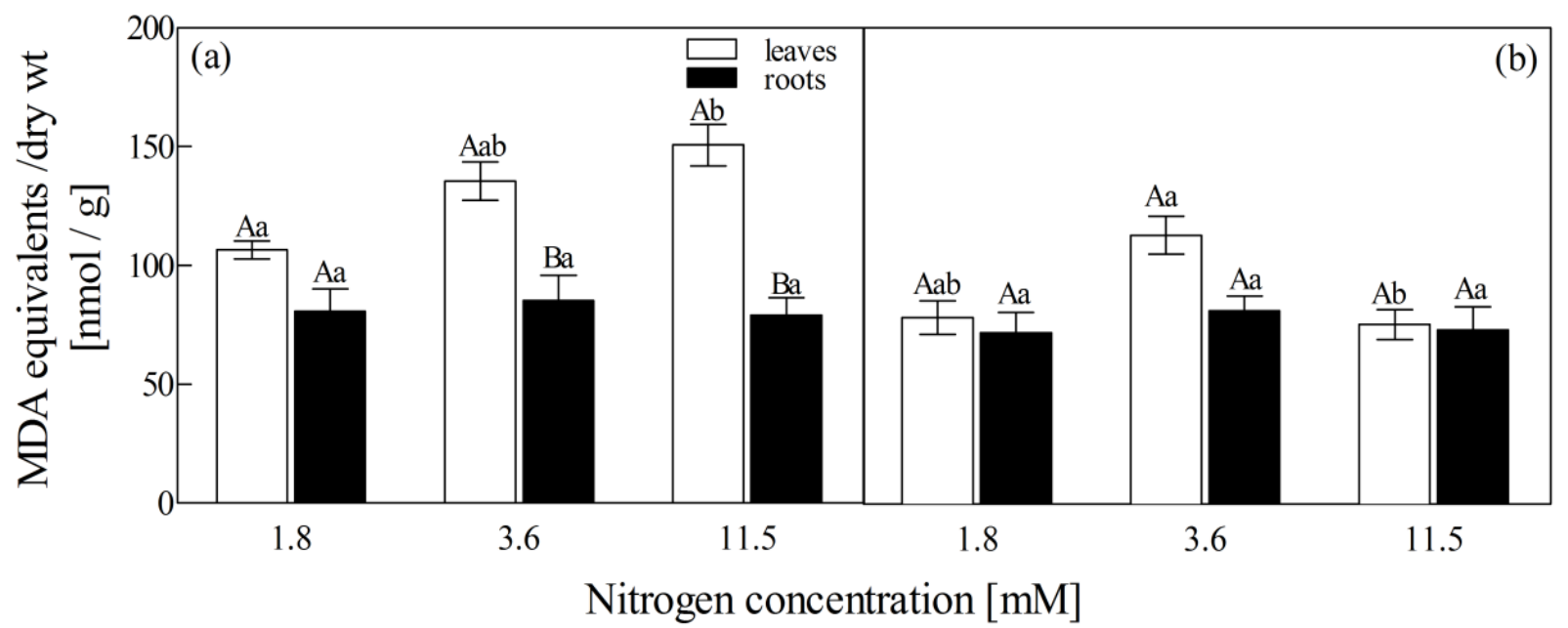

Fig. 3. Effect of nitrogen treatments on leaf and root lipid peroxidation of younger (a) and older (b) basil plants.

Vertical bars represent $\pm S E(n=3)$. Means with the different letter are significantly different from each other (Tukey test, $\mathrm{p}<0.05)$. Capital letters represent comparison between leaves and roots. Lower case letters represent comparison between nitrogen treatments

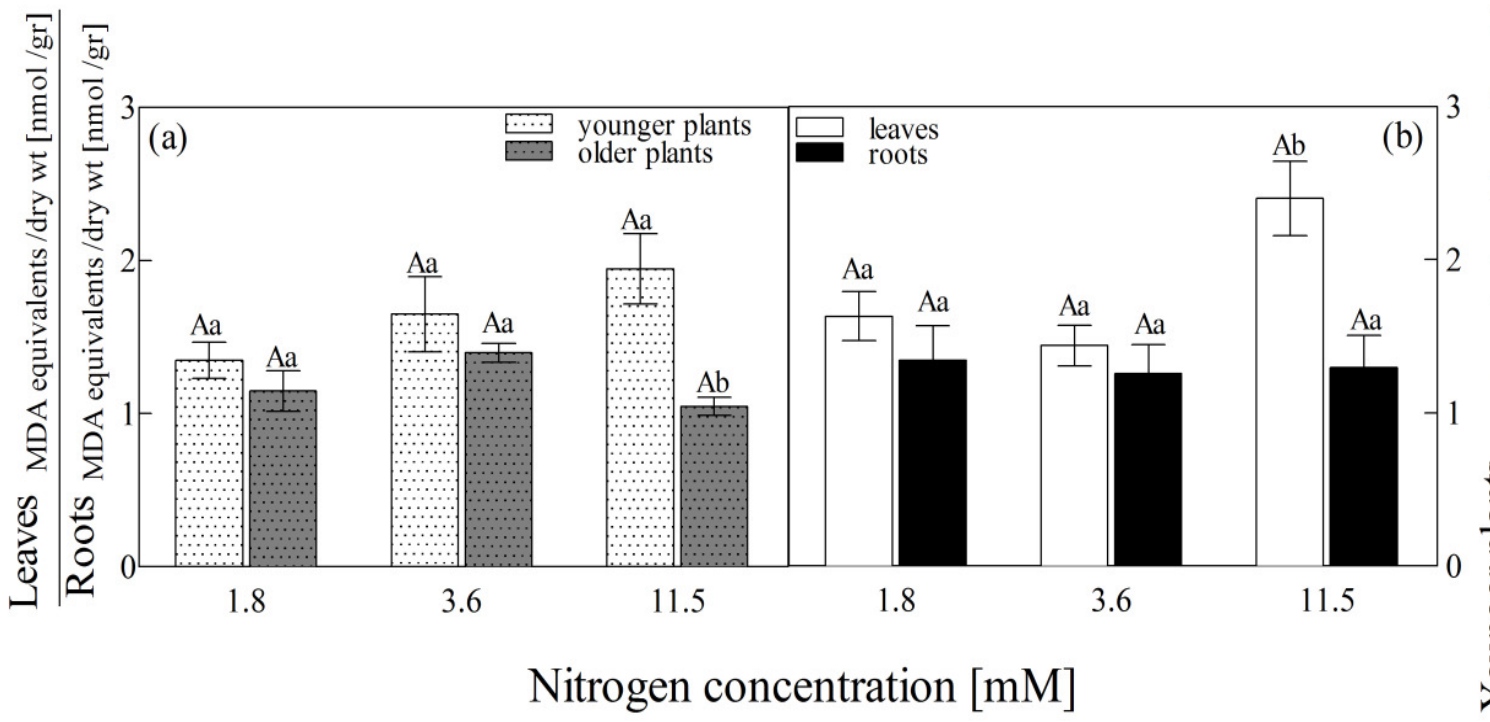

Fig. 4. Effect of nitrogen treatments on a) leaves to roots and b) younger to older plants lipid peroxidation ratios Vertical bars represent $\pm S E(n=3)$. Means with the different letter are significantly different from each other (Tukey test, $\mathrm{p}<0.05)$. Capital letters represent comparison between i) younger and older plants (panel (a)) and ii) leaves and roots (panel (b)). Lower case letters represent comparison between nitrogen treatments 
566

In spite of the above alterations, it is considered that in basil plants the increased $\mathrm{N}$ nutrition decreases both phenolics concentration and antioxidant activity (Nguyen and Niemeyer, 2008; Kiferle et al., 2013) while enhances the accumulation of essential oils (Sifola and Barbieri, 2006; Nurzynska-Wierdak et al., 2013) which also exhibit antioxidant activity (Amorati et al., 2013). These contradictious findings correspond to our results which indicate that aeroponically treated high $\mathrm{N}$ nutrition enhances both the enzymic antioxidative defense in leaves and roots and the leaf oxidative damages, implying that $\mathrm{N}$ nutrition induces oxidative stress while the plants develop adaptations of their enzymic and non-enzymic antioxidant defense. Therefore, it is quite ambiguous whether the increased $\mathrm{N}$ concentrations improve antioxidative defense as it has been proposed for other plants (Štajner et al., 1997; Zhang et al., 2014) or induce oxidative stress.

\section{Conclusions}

Basil oxidative stress responses (lipid oxidative damage and CAT antioxidative defense) against $\mathrm{N}$ nutrition appear to be more intense in leaves than in roots, especially in younger plants. Moreover, the strong CAT activity response in both leaves and roots in comparison with the relatively weak lipid damage (only in leaves) indicates a sufficient plant antioxidative defense adaptation. Further research, concerning other antioxidative defense or cellular oxidative damage indexes will clarify better the oxidative role of $\mathrm{N}$ nutrition especially at the conventional concentrations used for this crop production in soilless culture.

In point of the different basil CAT activity profiles between leaves and roots they may reflect the dominance of different isoenzymes as it is affirmed by their differential sensitivity against aminotriazole.

\section{Acknowledgements}

This work was supported by the European Union (European Social Fund - ESF) and Greek national funds through the Operational Program "Education and Lifelong Learning" of the National Strategic Reference Framework (NSRF) - Research Funding Program: ARCHIMEDES III (MIS 383566) - investing in knowledge society through the European Social Fund.

\section{References}

Amorati R, Foti MC, Valgimigi L (2013). Antioxidant activity of essential oils.Journal of Agricultural and Food Chemistry 61:10835-10847.

Assimakopoulos SF, Mavrakis AG, Grintzalis K, Papapostolou I, Zervoudakis G, Konstantinou D, Chroni E, Vagianos CE, Georgiou C (2008). Superoxide radical formation in diverse organs of rats with experimentally induced obstructive jaundice. Redox Report 13:179 184.

Azevedo RA, Alas RM, Smith RJ, Lea PJ (1998). Response of antioxidant enzymes to transfer from elevated carbon dioxide to air and ozone fumigation, in the leaves and roots of wild-type and a catalase-deficient mutant of barley. Physiologia Plantarum 104:280-292.

Blum J, Fridovich I (1983). Superoxide, hydrogen peroxide, and oxygen toxicity in two free-living nematode species. Archives of Biochemistry and Biophysics 222:35-43.
Buege JA, Aust SD (1978). Microsomal lipid peroxidation. Methods in Enzymology 52:302-310.

Chen L, Liu S-C, Gai J-Y, Zhu Y-L, Yang L-F, Wei G-P (2009). Effects of nitrogen forms on the growth, ascorbate-glutathione cycle and lipid peroxidation in developing seeds of vegetable soybean. African Journal of Agricultural Research4:1178-1188.

Chouliaras V, Dimassi K, Therios I, Molassiotis A, Diamantidis G (2004). Root-reducing capacity, rhizosphere acidification, peroxidase and catalase activities and nutrient levels of Citrus taiwanica and $C$. volkameriana seedlings, under Fe deprivation conditions. Agronomie 24:1-6.

Dias MC, Figueiredo P, Duarte IF, Gil AM, Santos C (2014). Different responses of young and expanded lettuce leaves to fungicide Mancozeb: chlorophyll fluorescence, lipid peroxidation, pigments and proline content. Photosynthetica 52:148-151.

Everett KT, Hawkins BJ, Mitchell AK (2010). Douglas-fir seedling response to a range of ammonium: nitrate ratios in aeroponic culture. Journal of Plant Nutrition33:1638-1657.

Guo S-W,Zhou Y, Gao Y-X, Li Y,Shen Q-R (2007). New insights into the nitrogen form effect on photosynthesis and photorespiration. Pedosphere 17:601-610.

HavirEA(1992). The in vivo and in vitro inhibition of catalase from leaves of Nicotiana sylvestris by 3-amino-1,2,4triazole. Plant Physiology 99:533537.

Hawkesford M, Horst W, Kichey T, Lambers H, Schjoerring J, Møller IS, White P (2012). Functions of macronutrients. In: Marschner P (Ed). Marschner's mineral nutrition of higher plants. Academic Press, San Diego, pp 135-189.

Kiferle C, Maggini R, Pardossi A (2013). Influence of nitrogen nutrition on growth and accumulation of rosmarinic acid in sweet basil (Ocimum basilicum L.) grown in hydroponic culture. Australian Journal of Crop Science 7:321-327.

Kiprovski B, Malenčić D, Popović M, Stojšsin V, Budakov D, Ćurčić Ž, Danojević D (2014). Correlation between lipid peroxidation and phenolics content in leaves and roots of sugar beet infected with Rhizoctonia solani. Phytoparasitica 42:199-203.

Loew O (1900). A new enzyme of general occurrence in organisms. Science 11:701-702

Mhamdi A, Noctor G, Baker A (2012). Plant catalases: peroxisomal redox guardians. Archives of Biochemistry and Biophysics 525:181-194.

Mhamdi A, Queval G, Chaouch S, Vanderauwera S, Breusegem FV, Noctor G (2010). Catalase function in plants: a focus on Arabidopsis mutants as stress-mimic models. Journal of Experimental Botany 61:4197-4220.

Nguyen PM, Niemeyer ED (2008). Effects of nitrogen fertilization on the phenolic composition and antioxidant properties of basil (Ocimum basilicum L.). Journal of Agricultural and Food Chemistry 56:86858691.

Nurzynska-Wierdak R, Borowski B, Dzida K, Zawislak G, Kowalski R (2013). Essential oil composition of sweet basil cultivars as affected by nitrogen and potassium fertilization. Turkish Journal of Agriculture and Forestry $37: 427-436$ 
Popov VN, Antipina OV, Trunova TI (2010). Lipid peroxidation during low-temperature adaptation of cold-sensitive tobacco leaves and roots. Russian Journal of Plant Physiology 57:144147.

Redinbaugh MG, Sabre M, Scandalios JG (1990). The distribution of catalase activity, isozyme protein, and transcript in the tissues of the developingmaize seedling. Plant Physiology 92:375-380.

Saneoka H, Moghaieb REA, Premachandra GS, Fujita K (2004). Nitrogen nutrition and water stress effects on cell membrane stability and leat water relations in Agrostis palustris Huds. Environmental and Experimental Botany 52:131-138.

Sifola MI, Barbieri G (2006). Growth, yield and essential oil content of three cultivars of basil grown under different levels of nitrogen in the field. Scientia Horticulturae 108:408-413.

Štajner D, Kevrešan S, Gašić O, Mimica-Dukić N, Zongli H (1997). Nitrogen and Azotobacter chroococcum enhance oxidative stress tolerance in sugar beet. Biologia Plantarum 39:441-445.

Taiz L, Zeiger E (2002). Plant Physiology. Mass: Sinauer Associates ( $\left.3^{\text {rd }} \mathrm{ed}\right)$, Sunderland.

Tang B, Xu S, Zou X, Zheng Y, Qiu F (2010). Changes of antioxidative enzymes and lipid peroxidation in leaves and roots of waterlogingtolerant and waterlogging-sensitive maize genotypes at seedling stage. Agricultural Sciences in China 9:651-661.

Tewari RK, Kumar P, Sharma PN (2007). Oxidative stress and antioxidant responses in young leaves of mulberry plants grown under nitrogen, phosphorus or potassium deficiency.Journal of Integrative Plant Biology 49:313-322.
Wang X, Tiu T, Li C (2012). Characterization of biogenic volatile organic compounds and membrane lipid peroxidation during leaf ageing in maize (Zea mays). Indian Journal of Agricultural Sciences 82:447-450.

Wei G-P, Yang L-F, Zhu Y-L, Chen G (2009). Changes in oxidative damage, antioxidant enzyme activities and polyamine contents in leaves of grafted and non-grafted eggplant seedlings under stress by excess of calcium nitrate. Scientia Horticulturae 120:443-451.

Willekens H, Inzé D, Montagu MV, van Camp W (1995). Catalases in plants. Molecular Breeding 1:207-228.

Zhang F-Q, Wang Y-S, Lou Z-P, Dong J-D (2007). Effect of heavy metal stress on antioxidative enzymes and lipid peroxidation in leaves and roots of two mangrove plant seedlings (Kandelia candel and Bruguiera gymnorbiza). Chemosphere 67:4450.

Zhang L-X, Li S-X, Zhang H, Liang Z-S (2007). Nitrogen rates and water stress effects on production, lipid peroxidation and antioxidative enzyme activities in two maize (Zea mays L.) genotypes. Journal of Agronomy and CropScience 193:387-397.

Zhang F, Wan X, Zheng Y, Sun L, Chen Q, Zhu X, Guo Y, Liu M (2014). Effects of nitrogen on the activity of antioxidant enzymes and gene expression in leaves of Populus plants subjected to cadmium stress. Journal of Plant Interactions 9:599-609.

Zobel RW, Del Tredici P, Torrey JG (1976). Method for growing plants aeroponically. Plant Physiology 57:344346. 